\title{
High Levels of New Neuron Addition Persist When the Sensitive Period for Song Learning Is Experimentally Prolonged
}

\author{
Linda Wilbrecht, ${ }^{1,4}$ Heather Williams, ${ }^{2}$ Nidhi Gangadhar, ${ }^{1,3}$ and Fernando Nottebohm ${ }^{1}$ \\ ${ }^{1}$ Laboratory of Animal Behavior, Rockefeller University, New York, New York 10021, ${ }^{2 B i o l o g y}$ Department, Williams College, Williamstown, Massachusetts \\ 01267, ${ }^{3}$ Department of Biological Sciences, Columbia University, New York, New York 10027, and ${ }^{4}$ Cold Spring Harbor Laboratory, Cold Spring Harbor, \\ New York 11724
}

\begin{abstract}
Socially reared zebra finch males imitate a song they hear during posthatching days 30 - 65; during this time, many new neurons are added to the high vocal center (HVC), a forebrain nucleus necessary for the production of learned song. New neuron addition drops sharply after day 65 , and no new songs are imitated. In contrast, male zebra finches reared in isolation from other males have more variable songs at day 65 and thereafter can still imitate new sounds (Eales, 1985). We show that, in isolate birds, a greater number of new neurons continues to be added to HVC during the next $85 \mathrm{~d}$, and this number correlates with syllable variability. We suggest that new neuron addition and turnover facilitate song change and that this effect lingers when an expected learning event is delayed.
\end{abstract}

Key words: neurogenesis; learning and memory; BrdU; birdsong; neuroethology; deprivation

\section{Introduction}

New neurons continue to be added to parts of the adult vertebrate brain (Altman, 1962; Kaplan and Hinds, 1977; Goldman and Nottebohm, 1983) where they become connected to existing networks (Paton and Nottebohm, 1984; van Praag et al., 2002) and replace cells that had died previously (Nottebohm, 1985; Kirn et al., 1993; Scharff et al., 2000). The benefits of this replacement are not understood. Examination of variables that affect new neuron addition in the song system provides the opportunity to relate addition and elimination of cells to changes in a natural, learned behavior.

The high vocal center (HVC) of the song system projects to the robust nucleus of the arcopallium (RA) which in turn projects to motor neurons of the hypoglossal nucleus that innervate muscles of the vocal organ, the syrinx (Nottebohm et al., 1976). RAprojecting neurons within HVC are replaced during development and continue to be replaced in adulthood (Alvarez-Buylla et al., 1988; Kirn et al., 1991). Each RA-projecting cell in HVC $(\mathrm{HVC} \rightarrow \mathrm{RA})$ fires only during a $6 \mathrm{~ms}$ window time-locked to a particular segment of song (Hahnloser et al., 2002). Approximately $200 \mathrm{HVC} \rightarrow$ RA neurons (assuming nonoverlapping windows and a $600 \mathrm{~ms}$ song motif) are thought to fire during each window, and the whole population fires in a sparse, serial manner that presumably encodes the learned song pattern (Fee et al.,

Received Nov. 11, 2005; revised June 29, 2006; accepted July 25, 2006.

This work was supported by Public Health Service Grants MH18343 and MH63132, Mr. Howard Phipps, the Mary Flagler Cary Charitable Trust, and a National Science Foundation Graduate Research Fellowship (L.W.). We thank Daun Jackson, Sharon Sepe, and Helen Ecklund for assistance with animal care and Tim Gardner and Casimir Wierzynski for assistance with song analysis.

Correspondence should be addressed to Dr. Linda Wilbrecht, 1 Bungtown Road, Svoboda Laboratory, Cold Spring Harbor Laboratory, Cold Spring Harbor, NY 11724. E-mail: wilbrech@cshl.org.

DOI:10.1523/JNEUROSCI.4869-05.2006

Copyright $\odot 2006$ Society for Neuroscience $\quad$ 0270-6474/06/269135-07\$15.00/0
2004). Previous work showed that relatively high levels of new neuron numbers in HVC correlate with developmental (AlvarezBuylla et al., 1988; Nordeen and Nordeen, 1988) or seasonal (Kirn et al., 1994) periods of song learning. To test this correlation between new neuron numbers and the capacity for song learning, we examined whether measures that extend the sensitive period for song learning also affect new neuron recruitment in HVC.

Zebra finches reared with adult males learn to imitate their song between days 30 and 65 (Immelmann, 1969; Eales, 1987; Boehner, 1990; Williams, 1990). This imitation is perfected and becomes more stereotyped during days 65-90. In contrast, juvenile male zebra finches reared in visual or auditory isolation from adult males improvise a song that they can still alter as young adults, after day 80, to match that of a live tutor (Eales 1985, 1987; Morrison and Nottebohm, 1993; Heinrich et al., 2003; Livingston et al., 2000); their sensitive period for song learning is said to remain open beyond the normal limit. Although this late imitation of a tutor's song is not as extensive as in younger birds (Morrison and Nottebohm, 1993), it may provide clues to the relationship between new neurons and song learning. Here, we show that (1) the song of individuals reared without an adult male companion ("isolates") is more variable after day 90 than that of individuals reared with adult male companions ("controls"); (2) the number of new HVC neurons added after day 65 is significantly higher in the isolates than in controls; and (3) there is a correlation between syllable variability and the number of new, recently added neurons.

\section{Materials and Methods}

Subjects. The 79 zebra finch (Taeniopygia guttata) males used for the present report were bred in our colonies at the Rockefeller University Field Research Center (Millbrook, NY). All protocols involving animals 
were approved by the Rockefeller University Animal Care and Use Committee and conformed with National Institutes of Health guidelines.

Housing. Standard isolation involved housing animals in ventilated sound-attenuation chambers [described by Morrison and Nottebohm (1993) and Tchernichovski et al. (2001)]. Figure 1a lists group numbers and describes the treatment that each group received. All birds followed a $12 \mathrm{~h}$ light/dark photoperiod. "Controls" were housed with their family (including father) from hatching until day 50; thereafter, they were treated the same as the isolates. "Standard isolates" were separated from their father at posthatching day 8 and subsequently did not see or hear another male; they were kept in a sound-attenuation chamber with their mother (females do not sing) and siblings until independence at day 30 , when the mother and siblings were removed. At day 80 (sexual maturity), another adult female was introduced to provide social stimulation to birds in the control and standard isolation groups (birds killed at day 90 were housed with females from day 65 on). Groups of controls and standard isolates were killed at $65,91,120,150$, and $180 \mathrm{~d}$ after hatching.

To investigate the effects of different types of isolation, we also looked at two more groups. "Visual isolates" were housed singly at day 30 in cages separated by opaque barriers such that they could hear, but not see, other adult males kept in the same room; these birds did not get a female companion. "Solo isolates" were placed singly in sound-attenuation chambers at day 30 and did not get a female companion. Because animal numbers and isolation space were limited, the visual isolate and solo isolate groups were included only for the age cohort killed at posthatching day 120 . Because the percentages of new HVC neurons recruited in the three groups of isolates were very similar (see Fig. 2), these three isolate groups were pooled for purposes of obtaining estimates of neuronal recruitment in 120-d-old isolates (see Fig. 1).

Tutoring isolated birds. To confirm that isolates can learn after the sensitive phase for auditory learning and to assess the relationship between new neuron number and amount of song learned, an additional six visual isolates were each given a singing adult male companion from days 80 to 150 . Starting at $120 \mathrm{~d}$ of age, each bird received, for $5 \mathrm{~d}$, daily systemic injections of the cell birth marker 5-bromo-2'-deoxyuridine (BrdU) (see below). All of these birds were killed at $150 \mathrm{~d}$ of age. The song of each bird was compared with that of its companion ("tutor") at 79 and $150 \mathrm{~d}$ (see below, Song analysis). The juveniles were recorded alone and thus sang undirected song; the tutors were recorded with the juveniles present and, therefore, may have sung male-directed or undirected song.

New neuron labeling. The addition of new neurons to the HVC of all birds was documented, as in the above tutored isolates, by five daily systemic injections $(0.08 \mathrm{mg} / \mathrm{g}$ body weight $)$ of $\mathrm{BrdU}$, a thymidine analog (Sigma, St. Louis, MO), followed by a $30 \mathrm{~d}$ survival period counting from the first injection (see Fig. 1a), which allowed the new neurons time to migrate into HVC and be incorporated into the song system circuitry (Kirn et al., 1999) before they were counted. The recruitment of BrdUlabeled neurons in isolates and controls was quantified at posthatching days $65,91,120,150$, and 180 .

Cell birth labeling, perfusion, and histology were performed exactly as described previously by Wilbrecht et al. (2002). Briefly, animals were perfused with $3 \%$ paraformaledehyde, and their brains were embedded in paraffin and sectioned sagitally at $6 \mu \mathrm{m}$ intervals and mounted on glass slides. These sections were used to estimate total HVC volume as well as for counts of neurons. Only right hemisphere sections were used in this study, because previous work has not seen right versus left differences in the recruitment of new HVC neurons. Antibodies against BrdU (DakoCytomation, High Wycombe, UK) were used to label new cells, and antibodies against $\mathrm{Hu}$ (Abcam, Cambridge, UK), an early expressing neuronal protein (Barami et al., 1995), were used to mark which of these cells were neurons.

Quantification of total and BrdU-labeled neuron numbers. For each animal, we estimated the volume of HVC by tracing the perimeter of HVC in cresyl violet-stained sections, and then calculated the area and multiplied it times the spacing $(120 \mu \mathrm{m})$ between sections. We then counted the cells that were BrdU+ and $\mathrm{Hu}+$ (i.e., the new HVC neurons) in 6-10 immunostained sections, ending our sampling when we had measured a $1 \mathrm{~mm}^{2}$ field for each animal. This sampling commenced in the center of HVC and extended approximately equally into the medial and lateral portions of the nucleus.

To understand the relative abundance of these new neurons, we also measured the density of total neurons $\left(\mathrm{Hu}+\right.$ cells) in three $0.012 \mathrm{~mm}^{2}$ fields from each of the same 6-10 sections. The number of new neurons and number of total neurons per unit of HVC volume was corrected according to section thickness and average nuclear diameter (Guillery and Herrup, 1997). From all of the above, we estimated the total number of neurons in HVC and the fraction of these cells that were BrdU+ and $\mathrm{Hu}+$ per $1000 \mathrm{Hu}+$ cells - those were the cells that had been born during the $5 \mathrm{~d}$ of BrdU injection and were still present $30 \mathrm{~d}$ later.

Song analysis. Typically, male zebra finches produce their song in "bouts." Each bout consists of several back-to-back repetitions of the bird's song "motif." A motif consists of several "syllables" separated by silent intervals (Immelmann, 1969; Boehner, 1990; Tchernichovski et al., 2001). We measured multiple aspects of song production in control zebra finches and in standard isolates in the presence of a female (see groups in Fig. 1) to see what aspects of song were correlated with new neuron numbers. Songs directed at females tend to be more stereotyped than undirected song (Jarvis et al., 1998), so by using recordings of males singing in the presence of females we hoped to get the most stable performance of which the birds were able. We made the following comparisons.

Syllable variability over a 3 week period. We compared each of 20 song motifs recorded the day before the bird was perfused to each of 20 song motifs recorded 3 weeks previously using Sound Analysis Software (Tchernichovski et al., 2000) (http://ofer.sci.ccny.cuny.edu/html/sound_ analysis.html). An individual that did not know which bird belonged to which group visually selected the first available motifs that included a comparable and complete array of syllables and that had no interrupting cage noises or female calls. Two measures determined by the Sound Analysis software, similarity (the percentage of a motif that reaches a criterion of $75 \%$ similarity or better when compared with a target motif) and accuracy (the averaged correspondence of acoustic features within the matching portions of the two motifs), were multiplied to obtain a similarity score for each comparison (the linearity term was omitted because it measures order rather than syllable structure). The 400 scores obtained in this manner for each individual were averaged to provide a measure of variability of syllable structure for the 20 birds for which appropriate song recordings were available (five isolate birds and five controls from each of the 120 and $150 \mathrm{~d}$ groups). A low similarity score indicates variability in syllable structure, whereas a high similarity score is typical of stereotyped song.

Same-day syllable variability. To look at syllable variability within a single day, we used the same motifs compared in the previous " 3 week variability analysis," but now we compared all 20 motifs recorded in a single day to each other (380 comparisons for the early recording and 380 for the late recording). The late recording similarity score, nearest the perfusion day, is shown in Table 1 . The early recording same-day similarity score is not shown.

Change in same-day syllable variability. To calculate change in sameday syllable variability, indicating stabilization or destabilization of song over time, we subtracted the similarity score obtained in the early recording from the score obtained in the later recording. Because comparison of the same motif to itself does not provide a perfect score of $100 \%$, both early and late scores were normalized by multiplication with the average score obtained when each motif was compared with itself. These normalized scores were then used for the subtraction indicating net gain (positive score difference) or loss (negative score difference) in syllable similarity.

Quantification of within-motif sequence variability. An observer that did not know to which group each bird belonged identified syllable sequence, or "song motif types" for each bird. For example, a bird with a canonical motif of seven syllables, "ABCDEFG" that also sang the truncated motifs "BCDEFG" and "ABCD" would have three motif types. We measured the frequency of each motif type in 100-200 songs recorded on the same day, shortly before the bird was killed, and calculated the minimum number of song motif types that together make up $80 \%$ of song production.

Quantification of amount of singing. To analyze the amount of singing, 
we averaged the number of song bouts produced by each bird in $1 \mathrm{~h}$ during 10 separate mornings 5-26 d after BrdU injection. Songs separated by $>1.5 \mathrm{~s}$ pauses were counted as part of separate bouts. The number of motifs per bout did not differ between isolates and controls (data not shown).

Assessment of imitation. Only a small subset of our isolates, the "tutored isolates," were ever exposed to a live male song model. To see how much these birds learned from their tutor, tutor and pupil song motifs were compared for each pupil both before and after introduction to the tutor. Imitation of a tutor was scored for each pupil by calculating the average similarity scores of 7-20 tutor song motifs (as many cleanly recorded canonical motifs as were available) to each of 20 pupil song motifs using Sound Analysis Software (a total of 140-400 comparisons for each time point). In both cases, the motifs were selected as described above. The comparisons were made at posthatching day 79, $1 \mathrm{~d}$ before introduction of the tutor, and day 150, the day of perfusion. We calculated net change in similarity by subtracting the similarity to the tutor before tutoring (at day 79) from similarity to the tutor after $70 \mathrm{~d}$ of exposure (at day 150). If the similarity between the tutor and pupil song was greater at 150 than at $79 \mathrm{~d}$, this was taken as evidence of imitation. It may be that some tutors are easier to imitate than others depending on how complex the tutor's song is or how close the tutor's song is to the juvenile's improvised song, but we did not control for these variables in this study.

Testosterone assay. At the time of perfusion, $50 \mu$ l plasma samples were taken from a wing vein, frozen, and later measured with Coat-A-Count Total Testosterone radioimmunoassay kit (DPC, Los Angeles, CA).

Statistical analysis. Comparisons of isolates and controls were done using a two-tailed Mann-Whitney $U$ test or a Kruskal-Wallis when there were more than two groups.

Regressions relating behavioral variables to new neuron numbers were performed in a stepwise manner. After performing the initial regression on new neuron number using a song variable using pooled data, we then added treatment group as a second variable (control vs isolate). If the explanatory power of the regression did not increase (as determined by values of $p$ and $r$ ), with the addition of the treatment group, we concluded that the correlation between the song variable and the number of new neurons was not attributable to large differences between treatment groups and that pooling the data was acceptable. Regressions were calculated using StatView (Abacus, Berkeley, CA). The threshold for significance was $p \leq 0.05$.

\section{Results}

We have previously shown that the addition of new neurons to nucleus HVC of juvenile zebra finch males is highest during early song learning and drops as song learning proceeds, particularly after posthatching day 60 (Wilbrecht et al., 2002). We now find that the drop in new neurons recruited after posthatching day 60 occurs later and is less acute in isolates than in socially reared, age-matched controls (Fig. 1b).

Interestingly, this effect does not seem to depend on how the birds were isolated. The number of new HVC neurons born on days 90-94 and counted on posthatching day 120 is similar for all groups of isolated birds, regardless of the isolation regimen (Fig. 2). Visual isolation has an effect on new neuron recruitment that is comparable with auditory isolation in sound-attenuation chambers either solo or with a female (Fig. 2). All of these forms of isolation have previously been shown to render birds capable of new song imitation after the normal close of the sensitive period (Morrison and Nottebohm, 1993).

By day 180, the isolates that had received BrdU injections on day 150 ceased to have a greater percentage of BrdU+ HVC neurons than controls (Fig. 1b). At that time, however, the total number of neurons in their HVC was higher than in controls, suggesting a higher retention of neurons added earlier (Table 1). At all other times, total HVC neuron numbers in isolates and controls were not significantly different (Table 1 ).
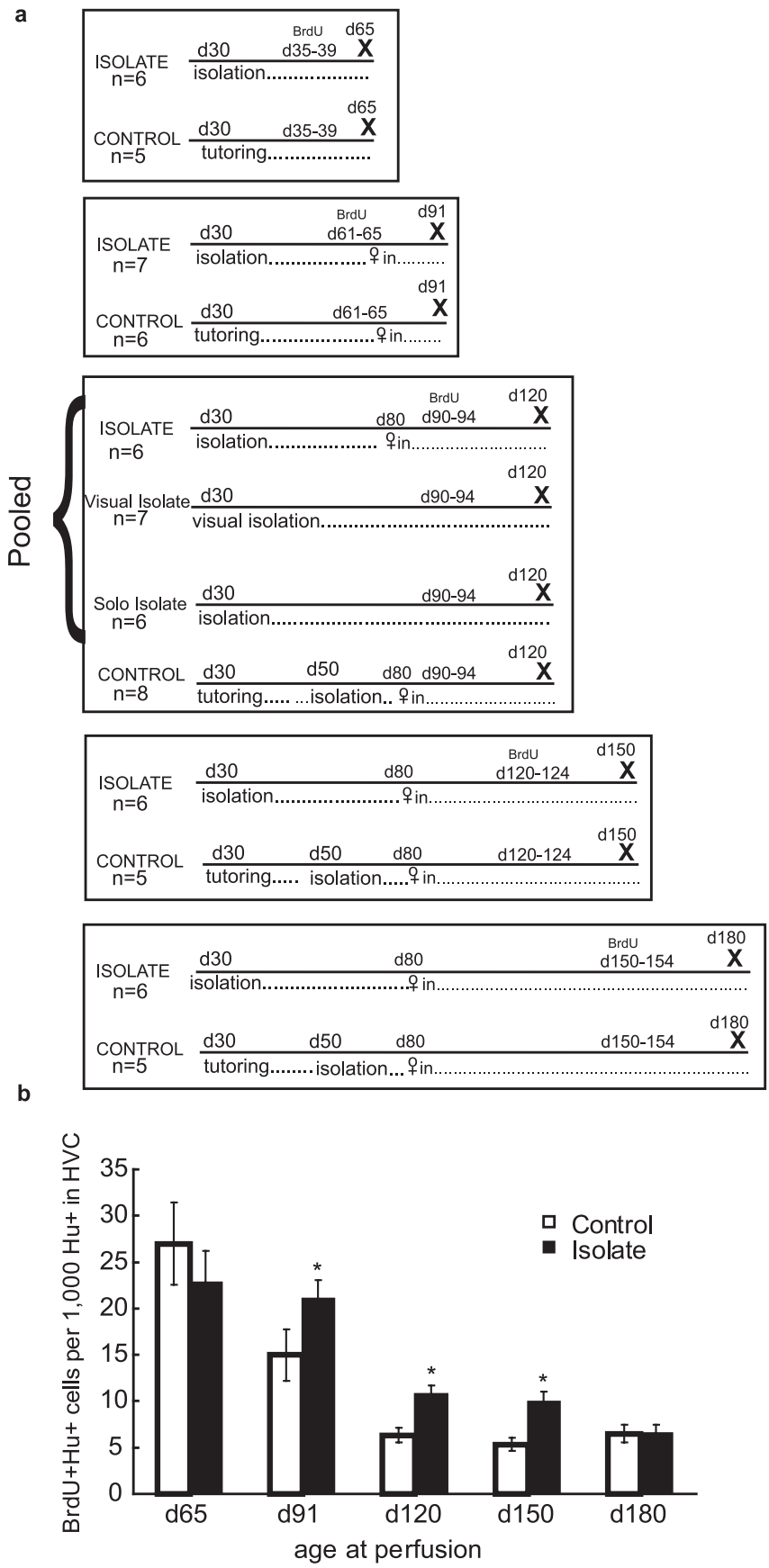

Figure 1. $\quad \boldsymbol{a}$ shows the different conditions under which the groups were housed and when they received BrdU injections. X marks the day of perfusion. $\boldsymbol{b}$ shows new neuron recruitment in isolates and controls. The $y$-axis shows the number of BrdU-labeled neurons per 1000 HVC neurons 25-30 d after injections. Error bars indicate SEM. The $x$-axis shows the posthatching day on which animals were killed. In birds killed after day 90 , there were more new neurons in the HVC of isolates than in that of controls. This difference was significant for the isolate groups at days 90, 120, and 150 (isolates vs controls, day 65: $U=21, p=0.33$; ${ }^{*}$ day $91: U=5, p=$ 0.02 ; ${ }^{*}$ day $120: U=19, p=0.01$; ${ }^{*}$ day $150: U=2, p=0.02$; day $180: U=16, p=0.93$ ).

It is well known that isolate songs are more variable, but this has not been well quantified using new song analysis tools. To assess song production in isolates in 120- and 150-d-old standard isolates and control birds (five in each of the four groups), we examined the following: (1) the variability of syllable structure between samples taken 3 weeks apart ("syllable variability over 3 weeks"); (2) syllable variability on $1 \mathrm{~d}$; (3) change in same-day variability over 3 weeks; and (4) within-motif syllable sequence 


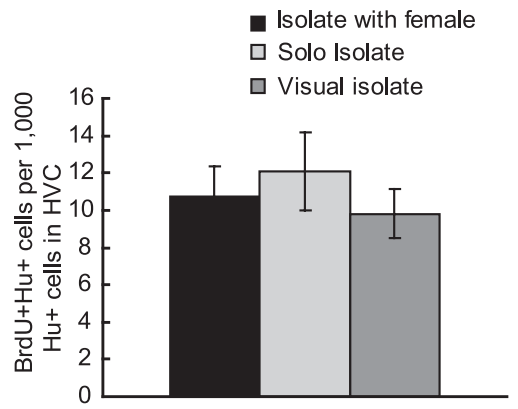

Figure 2. The number of new neurons found in different isolate groups on day 120. Each of the three groups of isolates was housed differently: "solo isolates" were housed singly in sound attenuation chambers, "isolates with female" were housed with a female from day 80 onward in sound attenuation chambers, and "visual isolates" were housed singly in cages where they could hear but not see other adult males in the same room. The three isolate groups did not differ from each other in new neuron counts ( $n=20$; Kruskal-Wallis, $0.86 ; p=0.65)$ but had significantly more new neurons than controls $(p<0.05)$. Error bars indicate SEM.

variability. The syllables of isolates were more variable than those of controls when compared over a 3 week period ending on days 120 and 150, yielding a lower similarity score (Table 1$)(p<$ 0.02 ). The syllables of isolates were also more variable than those of controls when recordings from the same day were compared (Table 1) $(p<0.02)$. When change in same-day variability was compared over the 3 week period, there was no significant difference between isolates and controls (Table 1) $(p>0.15)$. This is not surprising, because same-day similarity scores of isolates were similar on days 120 and 150, and the same applied to controls [i.e., isolates remained relatively unstable ( similarity score of $\sim 65 \%$ ) and controls remained stable (similarity score of $\sim 80 \%)$ ). When we looked at within-motif sequence variability, what some might call syntax, we found that again isolates were far more variable in their production of syllables (Table 1$)(p<$ $0.02)$.

Stereotyped behaviors are harder to modify than variable ones, and for this reason, we conjectured that if new neurons played a permissive role in extended song learning, then we would expect the number of new neurons in HVC would correlate with measures of behavioral variability. When the two populations (standard isolates and controls) were pooled, there was a significant correlation between the variability of syllables recorded on the day before perfusion and new neuron number (Fig. $3 ; r=-0.605, n=20, p=0.0047)$; birds with large numbers of new neurons had lower syllable similarity scores. Correlations between new neuron number and all other song measures were not significant or were not considered significant because the effect was not independent of control versus isolate group effects (assessed using a stepwise multiple regression). We assume that because of the time it takes new HVC neurons to migrate, differentiate, connect, and undergo initial culling (Kirn et al., 1999), the measure of syllable variability drawn from the final recording, which was significantly related to new neuron number, was the measure most likely to be related to the counts of labeled neurons made at the time the bird was killed.

We also measured testosterone levels and amount of singing in a subset of our birds (Table 1). These variables have been known to affect new neuron number in adult canaries (Li et al., 2000; AlvarezBorda et al., 2004). The amount of singing was similar in our controls and isolates, and their blood testosterone levels were comparable at every age measured (Table 1 ).

Using the 18 birds for which all measures were available, we used a multiple regression to assess the relative importance of the relationships between new neurons and testosterone, singing rate, age, same-day syllable variability (within the final recording), and variability of syllable order delivery. Among the individual variables, only same-day syllable variability $(p=0.012)$, but not age $(p=0.29)$, singing rate $(p=0.17)$, circulating testosterone $(p=0.57)$, or variability of syllable order $(p=0.65)$, significantly contributed to the overall power of the regression for predicting the number of new neurons observed in HVC.

After we housed six 80-d-old visual isolates with live tutors for $70 \mathrm{~d}$, five of six modified their isolate song to make it more similar to that of their tutor by day 150 (average change in similarity score, +8.82; SD, 8.71), whereas the song of one bird became slightly less similar to that of its tutor $(-1.17)$ (Fig. 4; supplemental Fig. 1, available at www.jneurosci.org as supplemental material). The number of new neurons in these birds fell halfway between controls and isolates of the same age (Table 1) and was not significantly different from either $(\mathrm{BrdU}+\mathrm{Hu}+/ 1000 \mathrm{Hu}+$ cells $=7.71 \pm 1.28 \mathrm{SEM})$. At day 150, 1 month after the end of BrdU administration, there was no significant correlation between number of BrdU+ neurons in HVC and similarity to the tutor at day $150(r=-0.32 ; p=0.53 ; n=6)$ or net change in similarity to the tutor (day 150 score minus day 79 score: $r=$ $-0.47, p=0.34, n=6)$.

\section{Discussion}

The number of neurons recruited to the HVC of juvenile male zebra finches reared with an adult male drops markedly after day 65 , the end of the auditory sensitive period for song imitation (Wilbrecht et al., 2002). After that time, these birds (our "controls") no longer imitate a new tutor and by day 90 their song has the stereotypy typical of adults. We supposed that, in isolates, whose song stereotypy is delayed and that can still imitate new models after day 65, addition of new HVC neurons would remain higher after that age. We found that isolates, when compared with controls, add $\sim 1.6$ times more neurons to HVC from posthatching days 65 to 150 .

The higher new neuron recruitment that we observed in isolates compared with controls can be ascribed to the absence of auditory and visual interactions with adult males between posthatching days 8 and 50. It cannot be attributed to the housing or treatment the isolates received after day 50 , because after that age control birds were also kept in isolation chambers (Fig. 1). The presence or absence of a female companion after day 80 did not affect the counts of new HVC neurons (Fig. 2).

Overall, 120- and 150-d-old isolates produced songs that were more variable than those of controls (Table 1). When the data of 120 - and 150-d-old isolates and controls were pooled, there was a significant correlation between the number of new HVC neurons and syllable variability on the day before perfusion (Fig. 3). Because the total number of HVC neurons did not differ significantly, at those ages, between isolates and controls, the excess in the number of new neurons must have been accompanied by increases in neuron turnover. Previous work has shown that $\mathrm{HVC} \rightarrow \mathrm{RA}$ neurons sparsely code the song motor program and direct the production of learned song (Nottebohm et al., 1976; Vu et al., 1994; Yu and Margoliash, 1996; Hahnloser et al., 2002; Cardin et al., 2005). Our correlations suggest that, when more HVC neurons are recently recruited and replaced, delivery of song is more variable.

The correlation between new neuron numbers and song variability is impressive given the complexity of the system. However, by virtue of its regression score, new neuron addition predicted only $\sim 35 \%$ of the variability in syllable structure. This leaves 
Table 1. Comparisons of controls versus isolates

\begin{tabular}{|c|c|c|c|c|c|c|}
\hline & & Day 65 & Day 91 & Day 120 & Day 150 & Day 180 \\
\hline \multirow[t]{2}{*}{ Estimated total neurons in HVC (SEM) } & Controls & $26,277(1,246)$ & $40,406(3,545)$ & $47,798(1,910)$ & $37,080(4,135)$ & $40,911(1,821)$ \\
\hline & Isolates & $27,140(3,421)$ & $40,437(1,826)$ & $41,207(2,979)$ & $39,111(3,318)$ & $* 56,336(3,448)$ \\
\hline \multirow[t]{2}{*}{ Amount of singing, bouts per hour (SEM) } & Controls & & & $107(12), n=6$ & $74(9), n=5$ & \\
\hline & Isolates & & & $86(8), n=6$ & $75(14), n=5$ & \\
\hline \multirow[t]{2}{*}{ Testosterone, ng/ml (SEM) } & Controls & & & $0.25(0.10), n=6$ & $0.68(0.37), n=5$ & $0.16(0.16), n=4$ \\
\hline & Isolates & & & $0.37(0.12), n=16$ & $0.44(0.15), n=5$ & $0.79(0.33), n=6$ \\
\hline \multirow[t]{2}{*}{ Syllable similarity over 3 weeks (SEM) } & Controls & & & $77.2(1.2), n=5$ & $80.1(0.6), n=5$ & \\
\hline & Isolates & & & $* 53.0(2.3), n=5$ & $* 60.2(3.4), n=5$ & \\
\hline \multirow[t]{2}{*}{ Syllable similarity on same day (SEM) } & Controls & & & $80.3(1.6), n=5$ & $82.2(0.9), n=5$ & \\
\hline & Isolates & & & $* 65.6(5.5), n=5$ & ${ }^{*} 68.8(3.0), n=5$ & \\
\hline \multirow[t]{2}{*}{ Change in same-day similarity over 3 weeks (SEM) } & Controls & & & $0.66(1.38), n=5$ & $0.56(1.01), n=5$ & \\
\hline & Isolates & & & $3.00(3.29), n=5$ & $1.67(2.83), n=5$ & \\
\hline \multirow[t]{2}{*}{ Minimum number of motif sequences in $80 \%$ of song (SEM) } & Controls & & & $2.6(0.5), n=6$ & $2.2(0.4), n=5$ & $2.7(0.9), n=5$ \\
\hline & Isolates & & & $* 11.7(3.9), n=6$ & $* 20.0(7.3), n=5$ & $8.2(3.9), n=6$ \\
\hline
\end{tabular}

Note: Lower song similarity scores indicate higher song variability.

${ }^{*} p<0.05$, isolates versus controls.

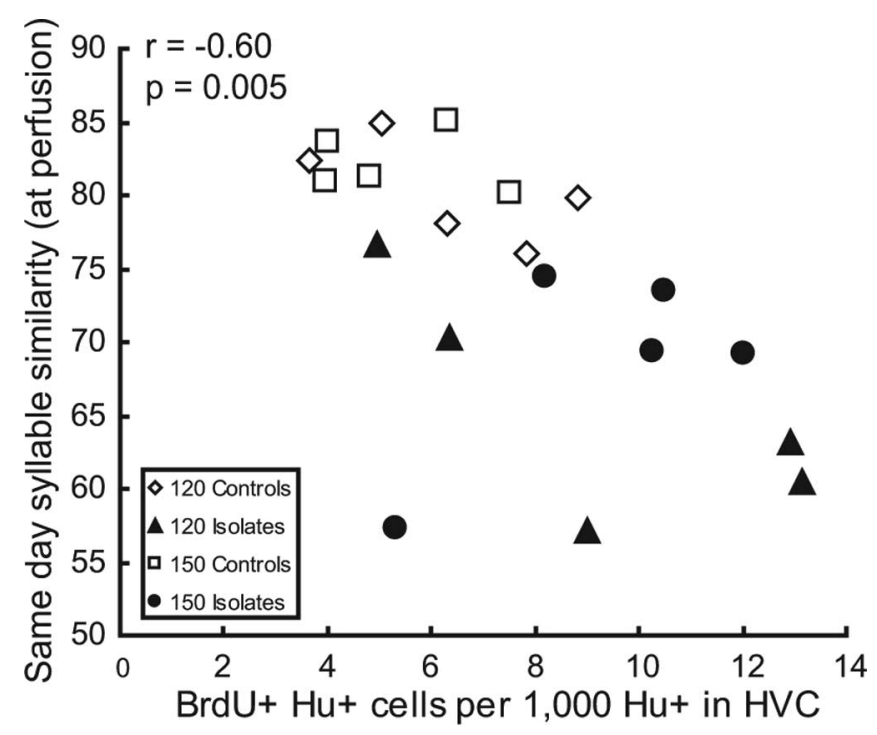

Figure 3. Syllable variability was greater in birds with larger numbers of new HVC neurons. Similarity scores for motifs sung on the day before perfusion (a measure of within-day variability in syllable structure) was significantly correlated with new neuron numbers ( $r=-0.605$; $n=20 ; p=0.0047$ ). Note that lower similarity indicates higher variability. This effect was not driven by differences between controls and isolates: adding the group membership variable did not change the significance of the relationship between syllable similarity and new neuron number (stepwise multiple regression).

ample room for other influences. The input of the lateral magnocellular nucleus of the anterior nidopallium (LMAN) to nucleus RA has been shown to make song more variable (Kao et al., 2005; Oelveczky et al., 2005), and age also clearly affects new neuron recruitment, even in isolates (Fig. 1b).

At $180 \mathrm{~d}$, we ceased to see a difference between controls and isolates in the proportion of new HVC neurons born 30 d earlier, but at that age the isolate HVCs had significantly more neurons than those of controls (Table 1). The significance of this unexpected gain in total neuron number at day 180 is not known. Because the gain apparently occurred after day 150, there may have been a decrease at this time in the culling of HVC neurons born earlier. Maybe the net gain was transient, to be eliminated by eventual reduction, or more neurons may be required to maintain a late acquired skill. Song learning in 180-d-old isolates has not been studied, but it has been noted that delayed song learning in isolates is not as accomplished as in juveniles (Eales 1987; Morrison and Nottebohm, 1993).

It is possible that new neuron recruitment in adult zebra finches serves a different purpose than recruitment during song learning, and in our long-term isolates these two functions are mingled. A previous study investigated the effect of social conditions on new neuron recruitment to HVC in male 4- to 5-monthold family reared zebra finches. After adult song had been in place for several weeks, these birds were housed just with a female companion or with $40-45$ other adult birds. $\left[{ }^{3} \mathrm{H}\right]$ Thymidine given immediately before the change in social setting revealed that twice as many HVC neurons born at that time were still present $40 \mathrm{~d}$ later in the birds housed in the more complex situation than in those housed as pairs (Lipkind et al., 2002). It is possible that HVC neurons born in adulthood play a role in song perception and their turnover is affected by the diversity of voices the adult bird must recognize (Williams and Nottebohm, 1985).

Previous work found that testosterone promoted the survival of new HVC neurons, but we did not see a correlation between new neuron numbers and testosterone levels. The correlation between blood testosterone levels and new neuron numbers came from observations comparing intact and castrated male canaries (Alvarez-Borda and Nottebohm, 2002) or comparing female canaries implanted with silasics filled with saline or testosterone (Rasika et al., 1994). The lack of a relationship between new neuron numbers and testosterone in our present study may have had to do with a species difference or with the fact that the range of testosterone levels found in our birds did not include extreme conditions.

Other studies have reported that testosterone levels are lower in 45 -d-old isolates than in normally reared controls, but this difference is gone by day 65 (Livingston et al., 2000). Testosterone can accelerate (White et al., 1999) and isolation can delay the maturation of NMDA-related postsynaptic currents at LMAN synapses in 45-d-old zebra finches; however, this difference is no 
longer evident at day 65 (Livingston and Mooney, 2001), and isolates can learn after the currents at these synapses have matured. Isolation can also delay the decline of NMDA receptor NR2B subunits found in LMAN at day 60 (Singh et al., 2000), but decline of these subunits also does not seem to interfere with song learning between days 65 and 90 (Heinrich et al., 2003).

Speculation that delays in maturation of NMDA receptors were responsible for holding open the sensitive period for learning were weakened when it was found that song imitation could occur after NMDA receptors had matured (Livingston et al., 2000; Heinrich et al., 2003). Will the relationship between learning and the recruitment of new neurons also come to be discounted? Three lines of reasoning argue that this lead is stronger: (1) the $\mathrm{HVC} \rightarrow \mathrm{RA}$ neurons are known to sparsely code learned song (Hahnloser et al., 2002); (2) higher rates of neuron recruitment persist in isolates versus controls, at least until posthatching day 150 , whereas the other factors, mentioned above, were only delayed before day 65 ; (3) there is a significant relationship between new neuron numbers and syllable variability. However, because the late song learning of isolates presented with a live model seldom achieves imitations that are as accurate and complete as those of socially reared juveniles (Morrison and Nottebohm, 1993; present study), it seems possible that the prompt and thorough imitation that young zebra finches achieve during the normal sensitive period for song learning requires both freshly minted HVC neurons and the variable input that LMAN provides to nucleus RA. Synchronous changes in these two (and other?) mechanisms could end the sensitive period for song learning under normal conditions.

The improvised song of isolate zebra finches is acquired by the interplay between motor experimentation and auditory feedback (Price, 1979) and so is a form of vocal learning. Nevertheless, song improvisation and song imitation must differ importantly, because imitation is followed by a sharp drop in new neuron recruitment, but improvisation is not. Perhaps the crucial difference between imitation and improvisation is that, only in the former is there a clearly perceived goal, model imitation, to which the bird is committed; under those conditions, the song system may produce a "mission accomplished" signal, which then blocks additional change. Improvisation, lacking such commitment to a target and, perhaps, such a putative signal, may leave the door open to additional change in behavior and neuronal turnover.

Many new neurons are added to the zebra finch HVC during the normal or extended sensitive period for song learning, suggesting a permissive relationship between new neurons and this form of learning. This is not the only example of such a relationship. Seasonal neuronal replacement in the HVC of adult canaries accompanies seasonal changes in the learned song repertoire (Kirn et al., 1994). New olfactory bulb neurons in adult female mice are born in early pregnancy and immediately after term (Shingo et al., 2003), and these neurons are probably important for maternal behavior and for the olfactory recognition of a dam's new pups. In wild adult chickadees, seasonal peaks in the recruitment of new hippocampal neurons correlate with seasonal peaks in food caching and retrieval (Barnea and Nottebohm, 1994). We suggest that when peaks in learning occur at predictable times of year or at predictable stages of development or reproduction,
Bird A: Imitated

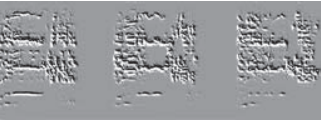

Bird B: Little Imitation

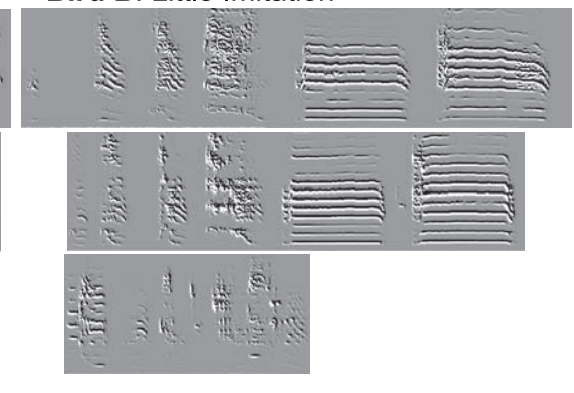

sec 0.7

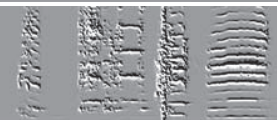

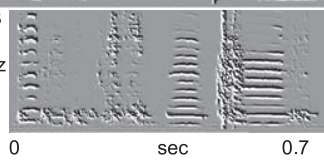

The nted with a live tutor after day 80 can achieve partial imitations, but sometimes do not imitate at all.
from two visual isolates before tutoring at day 79 . The middle panel shows their songs after tutoring becomes more similar to the tutor's song, shown at bottom [change in average similarity score for sons), $+24 \%]$. The song of bird B does not become more similar to the tutor's over the course of in score, $-1 \%)$. Note that repeated notes and calls are common in isolate song.

they may coincide with or even be preceded by peaks in new neuron availability. In the present report, we show that, when an expected peak in memory load, which normally occurs during the sensitive period for song learning, is delayed, juvenile rates of new neuron recruitment linger, as if waiting for this event.

\section{References}

Altman J (1962) Are new neurons formed in the brains of adult mammals? Science 135:1127-1128.

Alvarez-Borda B, Nottebohm F (2002) Gonads and singing play separate, additive roles in new neuron recruitment in adult canary brain. J Neurosci 22:8684-8690.

Alvarez-Borda B, Haripal B, Nottebohm F (2004) Timing of brain-derived neurotrophic factor exposure affects life expectancy of new neurons. Proc Natl Acad Sci USA 101:3957-3961.

Alvarez-Buylla A, Theelen M, Nottebohm F (1988) Birth of projection neurons in the higher vocal center of the canary forebrain before, during and after song learning. Proc Natl Acad Sci USA 85:8722-8726.

Barami K, Iversen K, Furneaux H, Goldman SA (1995) Hu protein as an early marker of neuronal phenotypic differentiation by subependymal zone cells of the adult songbird forebrain. J Neurobiol 28:82-101.

Barnea A, Nottebohm F (1994) Seasonal recruitment of hippocampal neurons in adult free-ranging black-capped chickadees. Proc Natl Acad Sci USA 91:11217-11221.

Boehner J (1990) Early acquisition of song in the zebra finch, Taeniopygia guttata. Anim Behav 39:369-374.

Brainard MS, Doupe AJ (2001) Postlearning consolidation of birdsong: stabilizing effects of age and anterior forebrain lesions. J Neurosci 21:2501-2517.

Cardin JA, Raksin JN, Schmidt MF (2005) Sensorimotor nucleus NIf is necessary for auditory processing but not vocal motor output in the avian song system. J Neurophysiol 93:2157-2166.

Eales LA (1985) Song learning in zebra finches: some effects of song model availability on what is learnt and when. Animal Behav 33:1293-1300.

Eales LA (1987) Song learning in female-raised zebra finches: another look at the sensitive phase. Anim Behav 35:1356-1365.

Fee MS, Kozhevnikov AA, Hahnloser RH (2004) Neural mechanisms of vocal sequence generation in the songbird. Ann NY Acad Sci 1016:153-170.

Goldman SA, Nottebohm F (1983) Neuronal production, migration and differentiation in a vocal control nucleus of the adult female canary brain. Proc Natl Acad Sci USA 80:2390-2394.

Gould E, Beylin A, Tanapat P, Reeves A, Shors TJ (1999) Learning enhances adult neurogenesis in the hippocampal formation. Nat Neurosci 2:260-265.

Guillery RW, Herrup K (1997) Quantification without pontification: choosing a method for counting objects in sectioned tissues. J Comp Neurol 386:2-7.

Hahnloser RH, Kozhevnikov AA, Fee MS (2002) An ultra-sparse code underlies the generation of neural sequences in a songbird. Nature 419:65-70.

Heinrich JE, Singh TD, Nordeen KW, Nordeen EJ (2003) NR2B down reg- 
ulation in a forebrain region required for avian vocal learning is not sufficient to close the sensitive period for song learning. Neurobiol Learn Mem 79:99-108.

Immelmann K (1969) Song development in the zebra finch and other Estrildid finches. In: Bird vocalizations (Hinde RA, ed), pp 61-74. London: Cambridge UP.

Jarvis ED, Scharff C, Grossman MR, Ramos JA, Nottebohm F (1998) For whom the bird sings: context-dependent gene expression. Neuron 21: 775-788.

Kao MH, Doupe AJ, Brainard MS (2005) Contributions of an avian basal ganglia-forebrain circuit to real-time modulation of song. Nature 433:638-642.

Kaplan MS, Hinds JW (1977) Neurogenesis in the adult rat: electron microscopic analysis of light radioautographs. Science 197:1092-1094.

Kirn J, Alvarez-Buylla A, Nottebohm F (1991) Production and survival of projection neurons in a forebrain vocal center of adult male canaries. J Neurosci 11:1756-1762.

Kirn J, O'Looughlin B, Kasparian S, Nottebohm F (1994) Cell death and neuronal recruitment in the high vocal center of adult male canaries are temporally related to changes in song. Proc Natl Acad Sci USA 91:7844-7848.

Kirn JR, Nottebohm F (1993) Direct evidence for loss and replacement of projection neurons in adult canary brain. J Neurosci 13:1654-1663.

Kirn JR, Fishman Y, Sasportas K, Alvarez-Buylla A, Nottebohm F (1999) Fate of new neurons in adult canary high vocal center during the first 30 days after their formation. J Comp Neurol 411:487-494.

Li XC, Jarvis ED, Alvarez-Borda B, Lim DA, Nottebohm F (2000) A relationship between behavior, neurotrophin expression, and new neuron survival. Proc Natl Acad Sci USA 97:8584-8589.

Lipkind D, Nottebohm F, Rado R, Barnea A (2002) Social change affects the survival of new neurons in the forebrain of adult songbirds. Behav Brain Res 133:31-43

Livingston FS, Mooney R (2001) Androgens and isolation from adult tutors differentially affect the development of songbird neurons critical to vocal plasticity. J Neurophysiol 85:34-42.

Livingston FS, White SA, Mooney R (2000) Slow NMDA-EPSCs at synapses critical for song development are not required for song learning in zebra finches. Nat Neurosci 3:482-488.

Morrison R, Nottebohm F (1993) Role of a telencephalic nucleus in the delayed song learning of socially isolated zebra finches. J Neurobiol 24:1045-1064.

Nordeen KW, Nordeen EJ (1988) Projection neurons within a vocal motor pathway are born during song learning in zebra finches. Nature 334:149-151.

Nottebohm F (1985) Neuronal replacement in adulthood. In: Hope for a new neurology (Nottebohm F, ed), pp 143-161. New York: New York Academy of Sciences.

Nottebohm F, Stokes TM, Leonard CM (1976) Central control of song in the canary, Serinus canaria. J Comp Neurol 165:457-486.

Oelveczky BP, Andalman AS, Fee MS (2005) Vocal experimentation in the juvenile songbird requires a basal ganglia circuit. PLoS Biol 3:e153.
Paton JA, Nottebohm F (1984) Neurons generated in the adult brain are recruited into functional circuits. Science 225:1046-1048.

Paton JA, Burd GD, Nottebohm F (1986) New neurons in an adult brain: plasticity in an auditory-motor nucleus. In: Biology of neural change (Rubel E, Ruben R, vanDeWater T, eds), pp 201-210. Amsterdam: Elsevier.

Price PH (1979) Developmental determinants of structure in zebra finch song. J Comp Physiol Psychol 93:260-277.

Rasika S, Nottebohm F, Alvarez-Buylla A (1994) Testosterone increases the recruitment and/or survival of new high vocal center neurons in adult female canaries. Proc Natl Acad Sci USA 91:7854-7858.

Scharff C, Nottebohm F (1991) A comparative study of the behavioral deficits following lesions of various parts of the zebra finch song system: implications for vocal learning. J Neurosci 11:2896-2913.

Scharff C, Kirn JR, Grossman M, Macklis JD, Nottebohm F (2000) Targeted neuronal death affects neuronal replacement and vocal behavior in adult songbirds. Neuron 25:481-492.

Shingo T, Gregg C, Enwere E, Fujikawa H, Hassam R, Geary C, Cross JC, Weiss S (2003) Pregnancy-stimulated neurogenesis in the adult female forebrain mediated by prolactin. Science 299:117-120.

Singh TD, Basham ME, Nordeen EJ, Nordeen KW (2000) Early sensory and hormonal experience modulate age-related changes in NR2B mRNA within a forebrain region controlling avian vocal learning. J Neurobiol 44:82-94.

Tchernichovski O, Nottebohm F, Ho CE, Pesaran B, Mitra PP (2000) A procedure for an automated measurement of song similarity. Anim Behav 59:1167-1176.

Tchernichovski O, Mitra PP, Lints T, Nottebohm F (2001) Dynamics of the vocal imitation process: how a zebra finch learns its song. Science 291:2564-2569.

van Praag H, Schinder AF, Christie BR, Toni N, Palmer TD, Gage FH (2002) Functional neurogenesis in the adult hippocampus. Nature 415:1030-1034.

Vu ET, Mazurek ME, Kuo YC (1994) Identification of a forebrain motor programming network for the learned song of zebra finches. J Neurosci 14:6924-6934.

Wang N, Hurley P, Pytte C, Kirn JR (2002) Vocal control neuron incorporation decreases with age in the adult zebra finch. J Neurosci 22:10864-10870.

White SA, Livingston FS, Mooney R (1999) Androgens modulate NMDA receptor-mediated EPSCs in the zebra finch song system. J Neurophysiol 82:2221-2234.

Wilbrecht L, Crionas A, Nottebohm F (2002) Experience affects recruitment of new neurons but not adult neuron number. J Neurosci 22:825-831.

Williams H (1990) Models for song learning: fathers or others? Anim Behav 39:745-757.

Williams H, Nottebohm F (1985) Auditory responses in avian vocal motor neurons: a motor theory for song perception in birds. Science 229:279-282

Yu AC, Margoliash D (1996) Temporal hierarchical control of singing in birds. Science 273:1871-1875. 